\title{
Chemical Composition of Cordia lutea L.: Absence of Pyrrolizidine Alkaloids
}

\author{
Iryna Mayevych ${ }^{1}$, Manuel López-Romero $\mathrm{J}^{1^{*}}$ and José Cabanillas ${ }^{2}$
}

${ }^{1}$ Department of Organic Chemistry, Faculty of Science, University of Málaga, 29071, Málaga, Spain

${ }^{2}$ Sabell Corp., Jr. Francisco de Orellana, 217, Of. 1, Santiago de Surco, Lima 33, Perú

\section{Abstract}

Cordia lutea is known for its medicinal value. This paper deals with a phytochemical investigation of this species, from which rutin, quercitin, linolenic acid, hexadecanoic acid and hexadecanoic acid glyceryl ester have been isolated as main the components. Alkaloids were not detected (UPLC-MS), indicating the absence of pyrrolizidine alkaloids (PAs). The absence of PAs in C. lutea implies no PAs toxicological risk for this plant.

Keywords: Pyrrolizidine alkaloids; Flavonoids; Quantification; Chemotaxonomy

\section{Introduction}

Pyrrolizidine alkaloids (PAs) are produced by numerous plant species in nature. Since much intoxication in animals and humans are attributed to the consumption of PAs, it is of interest to study their presence in plants. These alkaloids can be classified in two groups, viz., those with a saturated necine moiety, which are non-toxic, and those with an unsaturated necine base which are hepatotoxic to mammals [1]. It is known that the family Boraginaceae contains PAs, and floridanine and macrophylline, have been identified in species of Cordia [2]. However, PAs were not found in other Boraginaceae species such as C. gilletii [3].

Cordia lutea is a flowering plant belonging to the pantropical genus Cordia (Boraginaceae). Being an indigenous plant of northern Peru, its flowers have been widely used in traditional Peruvian medicine as a homeostatic drug, for the treatment of hepatic disorders and scurvy (Vitamin C deficiency) [4].

This paper reports on the chemical composition of the whole $C$. lutea plant (roots, stems, leaves, and flowers) in order to determine the presence or absence of PAs. To the best of our knowledge, to date no study has been carried out on the chemical profile of $C$. lutea.

\section{Materials and Methods}

\section{Materials}

C. lutea specimens were collected in the Tumbes river valley (La Capitana, Perú) and identified by Dr. Felicia Díaz Jarama (Universidad Nacional de la Amazonia Peruana) where a voucher specimen was deposited (36532, Herbarium Amazonense, AMAZ). Botanic synonyms of this plant are Cordia marchionica Drake and Cordia rotundifolia $\mathrm{R} \& \mathrm{P}$, while many common names were found to be used for this plant, e.g., overo, alkka mallki, biyuyo, caujaro, gomo, gomo amarillo, murciélago or ubito [4].

\section{Methods}

Plant extraction: In a $5 \mathrm{~L}$ Soxhlet apparatus the whole plant (dried and powdered; $1.1 \mathrm{~kg}$ ) was extracted with hexane $(3 \mathrm{~L}, 3 \mathrm{~h})$. The hexane extract was concentrated to dryness under vacuum to give a orange syrup ( $25 \mathrm{~g}$ ). Soxhlet extraction of the defatted plant was then carried out with methanol $(4 \mathrm{~L}, 7 \mathrm{~h})$. The methanol extract gave negative in a Mayer's reagent test. The methanol was removed under vacuum to give the crude methanolic extract (CME) as brownish syrup $(310 \mathrm{~g})$. A portion of the crude methanolic extract $(78 \mathrm{~g})$ was treated with a solution of $\mathrm{H}_{2} \mathrm{SO}_{4}$ in water $(2 \mathrm{M}, 0.5 \mathrm{~L})$ and stirred overnight with an excess of $\mathrm{Zn}$ dust for $\mathrm{N}$-oxide reduction [5]. After filtration, the acidic solution was washed with chloroform $(3 \times 150 \mathrm{~mL})$. The aqueous solution was basified with $30 \%$ aqueous $\mathrm{NH}_{3}(\mathrm{pH}>9)$. The basic mixture was then extracted with chloroform $(3 \times 100 \mathrm{~mL})$. The organic extract was washed with water, dried over anhydrous $\mathrm{MgSO}_{4}$, filtered and concentrated under vacuum to dryness to give yellowish syrup $(>0.2$ g). The Mayer's reagent test of this sample was negative.

Sample for UPLC analysis: Cordia lutea ground plant material (206 mg) was extracted with $2 \%$ formic acid $(15 \mathrm{~mL})$. An excess of zinc dust was added to the formic acid solution and shaken for $2 \mathrm{~h}$. Heliotrine $(100 \mu \mathrm{g} / \mathrm{mL}$ in methanol) was added as an internal standard to a concentration of $1 \mu \mathrm{g} / \mathrm{mL}$. An aliquot of the extract was diluted with water and injected into the UPLC-MS system. A similar procedure was carried out without $\mathrm{Zn}$ reduction (starting from $198 \mathrm{mg}$ of powdered plant).

Non-alkaloidal content: The crude methanolic extract (CME, 70 g) was treated with ethyl acetate $\left(500 \mathrm{~mL}, 4 \mathrm{~h}\right.$ and $\left.30^{\circ} \mathrm{C}\right)$. The organic layer was decanted and the solvent was removed under vacuum to give brown syrup $(4.1 \mathrm{~g})$. The residue was then extracted with more ethyl acetate $(2 \times 300 \mathrm{~mL})$ under reflux to give the second crude acetate extract $(7.2 \mathrm{~g})$. Crudes were separated by $\mathrm{SiO}_{2}(40-63 \mu \mathrm{m})$ flash column chromatography eluting with mixtures of $\mathrm{CH}_{2} \mathrm{Cl}_{2}: \mathrm{MeOH}$ in ascending methanol.

${ }^{1} \mathrm{H}$ and ${ }^{13} \mathrm{C}$ NMR spectra were recorded with a $400 \mathrm{MHz}$ ARX 400 Bruker spectrometer by using the residual solvent peak in $\mathrm{CDCl}_{3}$ $\left(\delta 7.24 \mathrm{ppm}, 400 \mathrm{MHz}\right.$, for ${ }^{1} \mathrm{H}$ and $\delta=77.0 \mathrm{ppm}, 100 \mathrm{MHz}$, for ${ }^{13} \mathrm{C}$ ). TLC analyses were performed on Merck silica gel 60 F 254 plates, and column chromatography was performed on silica gel $60(0.040$ $0.063 \mathrm{~mm}$ ). Mass spectrometry was carried out in a Waters Quattro microGC instrument using the GC injection mode in an Agilent 7890A chromatograph and electron ionization (EI) mode or in a Waters Synap G2 mass spectrometry system coupled to an UPLC Acquity H Class.

*Corresponding author: Manuel López-Romero J, Department of Organic Chemistry, Faculty of Science, University of Málaga, 29071, Málaga, Spain, Tel: +34952137383 E-mail:jmromero@uma.es

Received April 24, 2015; Accepted October 23, 2015; Published October 26, 2015

Citation: Mayevych I, López-Romero JM, Cabanillas J (2015) Chemical Composition of Cordia lutea L.: Absence of Pyrrolizidine Alkaloids. Nat Prod Chem Res 3: 194. doi:10.4172/2329-6836.1000194

Copyright: (c) 2015 Mayevych I, et al. This is an open-access article distributed under the terms of the Creative Commons Attribution License, which permits unrestricted use, distribution, and reproduction in any medium, provided the original author and source are credited. 


\section{Results}

Plant material was extracted with hexane in order to remove nonpolar compounds and then with methanol up to negative Mayer's Test. The obtained Crude Methanolic Extract (CME) was separated by acid-base treatment in order to isolate the alkaloids (see Materials and Methods). The alkaloidal fraction weigh was $<0.2 \mathrm{~g}$, being negative to the Mayer's Test. Analyses of this fraction by ${ }^{1} \mathrm{H}$ NMR and GC-MS were carried out to establish the presence or absence of PAs according to the method described by Frölich. This gives a high level of resolution (2 ppm) by using the PA heliotrine as the standard [6]. Retention times (Rts), molecular ions and MS fragmentation patterns were used as the diagnostic criteria. The analysis did not indicate the presence of pyrrolizidine alkaloids.

To confirm this result, an alternative specific UPLC analysis for PAs detection was also carried out [7]. Cordia lutea ground plant material was extracted with diluted formic acid. The resulting solution was treated with an excess of zinc dust to reduce the possible PAs $\mathrm{N}$-oxides. An aliquot of the extract was diluted with water and injected into the UPLC-MS system, by using Heliotrine as an internal standard (see Materials and Methods). Pyrrolizidine alkaloids were not detected. A similar procedure was carried out without $\mathrm{Zn}$ reduction and PAs were not detected by the UPLC-MS system.

In order to study the chemical composition of this plant regarding flavonoids and related compounds, a portion of the crude methanolic extract was extracted with portions of ethyl acetate by following a reported procedure [8]. Acetate extracts crudes were separated by $\mathrm{SiO}_{2}$ flash column chromatography and rutin, quercitin, linolenic acid, hexadecanoic acid (palmitic acid) and hexadecanoic acid glyceryl ester were isolated (Table 1 and Figure 1). Compounds were identified by a comparison of their spectral features with the reported data.

In conclusion, no PAs were detected in extracts of the Peruvian specimen of Cordia lutea. About 350 species make up the Cordia genus and to date only two species, Cordia sinensis and Cordia myxa, have been reported to contain the PAs floridanine and macrophylline, respectively [2]. The presence of PAs in these species suggests that other species in this genus may be able to synthesize PAs and a systematic study of the genus is justified using the methods described in this paper. The absence of PAs in C. lutea sample studied suggests no toxicological risk due to PAs for this plant. Moreover, no traces of alkaloids were detected with Mayer's Reagent, GC-MS or UPLC-MS

\begin{tabular}{|c|c|c|}
\hline Entry & Compound & \% of CME \\
\hline 1 & Rutin & 0.14 \\
\hline 2 & Quercitin & 0.10 \\
\hline 3 & Linolenic acid & 0.13 \\
\hline 4 & Palmitic acid & 0.13 \\
\hline 5 & Hexadecanoic acid glyceryl ester & 0.06 \\
\hline
\end{tabular}

Table 1: Main chemical composition of Cordia lutea

techniques. Known flavonoids and fatty acid esters were identified as the main chemical components of C. lutea.

\section{Acknowledgements}

The authors are very grateful to Sabell Corporation for their financial support, and to CICYT, Spain, Project CTQ13-48418-P, FEDER funds.

\section{References}

1. Mattocks AR (1989) Chemistry and toxicology of pyrrolizidine alkaloids Academic Press, New York, USA

2. Wassel G, El-Menshawi B, Saeed A, Mahran G, Reisch J (1987) New sources of pyrrolizidine alkaloids: Genus Cordia (Ehretiaceae) and Schismus (Gramineae). Scientia Pharm 55: 163-166.

3. Okusa PN, Beuerle T, Stévigny C, Due P (2012) Absence of pyrrolizidine alkaloids in Cordia gilletii De Wild (Boraginaceae). Biochem Syst Ecol 41: 1-2.

4. García-Cienfuegos BC (2006) Caracterización morfotaxonómica y fitoquímica de especies florísticas reportadas como etnomedicinales en la Reserva Nacional de Tumbes. I Congreso Latinoamericano de Mujeres en Ciencia, La Paz - Bolivia.

5. Asibal CF, Gelbaum LT, Zalkov LH (1989) Pyrrolizidine alkaloids from Heliotropium rotundifolium. J Nat Prod 52: 726-731.

6. Frolich C, Hartmann T, Ober D (2006) Tissue distribution and biosynthesis of 1,2-saturated pyrrolizidine alkaloids in Phalaenopsis hybrids (Orchidaceae). Phytochemistry 67: 1493-1502.

7. Joosten L, Mulder PPJ, Vrieling K, van Veen JA, Klinkhamer PGL (2010) The analysis of pyrrolizidine alkaloids in Jacobaea vulgaris; a comparison of extraction and detection methods. Phytochem Anal 21: 197-204.

8. Xu W, Chu K, Zhang Y, Huang M, Sha M, Chen L (2013) Isolation and identification of compounds from Bauhinia championii (Benth.). Benth Int $J$ Phytomed 5: 79-84.

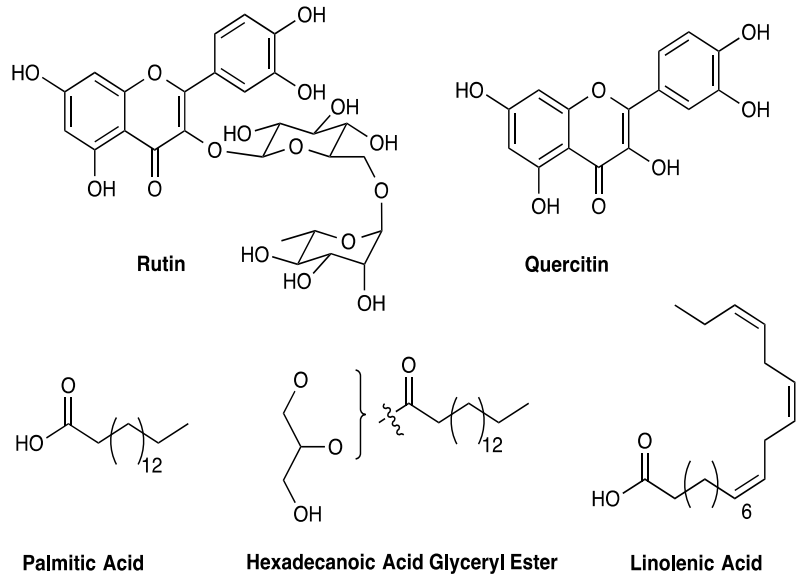

Figure 1: Isolated compounds from Cordia lutea. 